\title{
As representações sociais dos discentes e egressos sobre a terapia ocupacional
}

\author{
Letícia Rocha Dutra' \\ Universidade Federal dos Vales do Jequitinhonha e Mucuri, Minas Gerais, Brasil \\ Paulo Afrânio Sant'Anna \\ Universidade Federal dos Vales do Jequitinhonha e Mucuri, Minas Gerais, Brasil
}

\begin{abstract}
Resumo: O presente estudo se propõe a identificar as representações sociais dos estudantes e egressos do curso de Terapia Ocupacional (TO), da Universidade Federal de Minas Gerais (UFMG), sobre sua profissão, buscando verificar diferentes estágios de constituição dessas representações ao longo do processo de formação, atuação e construção da identidade profissional. Participaram do estudo, acadêmicos e discentes $(n=100)$ divididos em três subgrupos (inicias, finais e egressos). Para a coleta de dados, foi aplicado um questionário de evocação livre de palavras, e as informações foram posteriormente processadas pelos softwares EVOC2005 e CHIC ${ }^{\circledR}$. Os resultados mostraram que, entre as palavras que compõem o núcleo central, somente "autonomia" e "independência" apresentaram alta representatividade nos três subgrupos. Durante toda a sequência da análise dos dados, esse binômio se destaca, como observado também na árvore hierárquica. Conclui-se que os acadêmicos e discentes, ao representarem a profissão, priorizam o fazer profissional, que pode estar relacionado com a dificuldade em definir e criar uma identidade profissional.
\end{abstract}

Palavras-chave: representação social; terapia ocupacional; identidade; psicologia; formação.

\section{THE SOCIAL REPRESENTATIONS ABOUT OCCUPATIONAL THERAPY BY STUDENTS AND GRADUATES}

\begin{abstract}
This study aims at identifying the social representations by students and graduates in the Occupation Therapy program at the Federal University of Minas Gerais (UFMG) about their profession. It also aims to identify different stages of establishing such representations throughout the training process, performance and construction of the professional identity. Students and graduates participated in the study $(n=100)$, which was divided into three subgroups (initial, final and graduates). A questionnaire was used for data collection which was then subsequently processed by EVOC2005 and $\mathrm{CHIC}{ }^{\circledR}$ software. The results showed that among the words that make up the core, only autonomous and independent exhibited high representation in the three subgroups. This binomial stands out throughout the following data analysis, as observed in the hierarchical tree. We conclude that students and graduates who represent the profession prioritize professional action (doing), which may be related to the difficulty in defining and creating a professional identity.
\end{abstract}

Keywords: social representation; occupational therapy; identity; psychology; training.

'Endereço de correspondência: Letícia Rocha Dutra, Rua Manoel Pereira da Silva, 58, apt 201, b 18, Bairro Chácara, Betim - MG. E-mail: leticiadutrato@gmail.com. 
LAS REPRESENTACIONES SOCIALES DE LOS ESTUDIANTES Y EGRESADOS DE LA CARRERA DE TERAPIA OCUPACIONAL

\begin{abstract}
Resumen: El presente estudio tiene como finalidad identificar las representaciones sociales sobre la profesión de los estudiantes y egresados de la carrera de Terapia Ocupacional de la Universidad Federal de Minas Gerais, buscando verificar las diferentes etapas de la constitución de estas representaciones a lo largo del proceso de formación, ejercicio y construcción de la identidad profesional. En este estudio participaron estudiantes y egresados $(n=100)$ divididos en tres subgrupos (nuevo ingreso, próximos a graduarse y egresados). Para la recolección de los datos se aplicó un cuestionario de evocación libre de palabras, posteriormente, estos fueron procesados por los programas EVOC2005 y CHIC ${ }^{\circledR}$. Los resultados mostraron que de entre las palabras que componen el núcleo central, solamente autonomía e independencia presentaron una alta representatividad en los tres grupos; durante toda la secuencia de análisis de datos, este binomio destaca, pudiéndose observar esto de igual manera en el árbol jerárquico. Se concluye que los estudiantes y egresados, al momento de representar su profesión, priorizan el ejercicio profesional, lo que puede estar relacionado con la dificultad en definir $y$ crear una identidad profesional.
\end{abstract}

Palabras clave: representación social; terapia ocupacional; identidad; psicología; formación.

\title{
Introdução
}

A representação social de uma profissão é construída por meio de um processo psicossocial marcado por valores, ideologias, conceitos e práticas provenientes de saberes institucionalizados (Universidade, Diretrizes Curriculares Nacionais, Conselho Profissional etc.) e de saberes construídos nos intercâmbios sociais (cenários das práticas, mídia, relações pessoais etc.). É na tensão e negociação entre essas duas dimensões, o instituído e o não instituído, que se configuram as representações sociais da profissão que articularão sentidos e indicarão direções às práticas profissionais. Esse processo ocorre no campo intersubjetivo, no qual sujeito e objeto se interpenetram no plano simbólico, constituindo-se mutuamente. Nesse sentido, as representações sociais da profissão são, ao mesmo tempo, componentes da identidade profissional (Novaes \& Souza, 2013).

A Terapia Ocupacional é uma profissão que, desde sua gênese, buscou se fundamentar no caráter terapêutico da ocupação e, em seu percurso histórico, tem lutado pela autonomia como classe profissional e pela legitimação de suas práticas. No entanto, a literatura revela que a profissão ainda é afetada pelo desconhecimento social, por uma conceituação polissêmica e por modelos de formação que remetem a orientações diversas que influenciam a construção da identidade profissional dos terapeutas ocupacionais (Branco, 2003; Caniglia, 2005; Nikel, 2007; Carvalho, 2010).

A identidade profissional é decorrente de concepções e sentimentos desenvolvidos no processo de socialização da profissão, constituindo um grupo de características que iguala e diferencia os membros de um grupo profissional quando comparado a outro. Além de ser um "conjunto de crenças inquestionáveis que constituem uma perspectiva única, partilhada pelos membros do grupo" (Carvalho, 2012, p. 368), também possibilita que os profissionais entendam como devem atuar durante o exercício profissional, inclusive quais métodos utilizar (Carvalho, 2012). 
Estudos indicam que, no campo da Terapia Ocupacional, alguns fatores contribuem para a formação da identidade profissional: 1) a inserção desse profissional na sociedade marcada, ora por uma incipiência sobre a profissão, ora pelo reconhecimento estigmatizado (a terapia ocupacional sendo entendida como mera ocupação), que a desvaloriza e faz com que seus profissionais se sintam desqualificados ou ainda desacreditados (Branco, 2003); 2) a falta de reconhecimento da profissão, sendo esse o principal desafio durante o exercício profissional do terapeuta ocupacional (Carvalho, 2010); 3) a imprecisão das definições da terapia ocupacional (Caniglia, 2005), as quais, em grande parte, focam nos recursos terapêuticos e nas inter-relações possíveis, poucas vezes focando no objeto de estudo da profissão (Nikel, 2007). Ao relacionar a terapia ocupacional à prática e aos recursos terapêuticos, a profissão acaba perdendo especificidade, uma vez que essas mesmas práticas e recursos também são reconhecidamente utilizados por outras classes profissionais (Branco, 2003); 4) o processo formativo se inicia com a graduação e se estende para o cenário profissional.

Na história da saúde pública brasileira, especificamente no final da década de 1980, uma mudança do paradigma marcado pelo binômio "saúde-doença", inaugurado na Reforma Sanitária e instrumentalizado pelo Sistema Único de Saúde (SUS), influenciou diretamente o modelo de capacitação dos profissionais para a área da saúde e apontou para a necessidade de formação de recursos humanos para atuarem no SUS.

Na busca da operacionalização dessa proposta, em 2000, o Ministério da Saúde e o Ministério da Educação criaram iniciativas voltadas para as mudanças na graduação, por meio da construção de projetos pedagógicos e currículos flexíveis e inovadores, os quais visam reorientar a formação no sentido de construir um perfil acadêmico e profissional com competências e habilidades para atuar na resolução dos problemas de saúde dos indivíduos e da coletividade (Conselho Nacional de Educação, 2001). Entre essas políticas, evidenciam-se as Diretrizes Curriculares Nacionais (DCN) para área da saúde e esse estudo foca as DCN do curso de graduação em Terapia Ocupacional, promulgada pelo Parecer CNE/CES n 6, de 19 de fevereiro de 2002 (Conselho Nacional de Educação, 2002). Esse parecer, ainda em vigor, implica as instituições de nível superior que oferecem o curso de terapia ocupacional na reestruturação de suas grades curriculares a partir dos parâmetros sugeridos nele. As DCN definem também os princípios, os fundamentos, as condições e os procedimentos da formação de terapeutas ocupacionais.

O presente estudo se propõe a identificar as representações sociais dos estudantes e egressos do curso de terapia ocupacional da Universidade Federal de Minas Gerais (UFMG) sobre sua profissão, buscando verificar diferentes estágios de constituição dessas representações ao longo do processo de formação e atuação profissional. Considerando que as representações sociais são, ao mesmo tempo, estáveis e dinâmicas, este artigo discute como as DCN da profissão, do modo como foram interpretadas e materializadas no Projeto Político Pedagógico (PPP) do curso estudado, permeiam a 
construção das representações sociais sobre a Terapia Ocupacional, favorecendo ou não a incorporação de valores e práticas instituídas. Além do currículo, contribuem para a formação da identidade profissional variáveis que precisam ser consideradas, entre elas, os cenários das práticas, em que as interações com outros profissionais de saúde e a população atendida irão contribuir para a ressignificação da profissão e de suas práticas.

\section{Método}

Estudo de natureza quantitativa de abordagem transversal, no qual foram utilizados os descritores em saúde - DeSC: Terapia Ocupacional, Identidade, Psicologia e Formação.

\section{Participantes}

O universo do presente estudo foi composto por discentes e egressos do curso de terapia ocupacional da Escola de Educação Física, Fisioterapia e Terapia Ocupacional (EEFFTO) da UFMG. ${ }^{2}$

Para a composição da amostra, foram identificados e estabelecidos, segundo os objetivos da pesquisa, três grupos: 1) 34 discentes do primeiro ano (primeiro e segundo períodos) do curso de terapia ocupacional; 2) 34 discentes do último ano (sétimo e oitavo períodos) do curso de terapia ocupacional e 3) 32 egressos formados entre 2011 e 2013, em um total de 100 participantes. A distribuição da amostra em três grupos teve por finalidade verificar as alterações das representações ao longo do processo formativo.

\section{Instrumentos e procedimentos}

O período da coleta de dados ocorreu após a realização do estudo piloto. O instrumento utilizado foi o questionário de evocação livre de palavras, construído a partir da Técnica de Associação Livre de Palavras (Talp), proposta por Vergés, como citado em Oliveira, Marques, Gomes e Teixeira (2005). O questionário foi dividido em três partes. A primeira, com informações como: faixa etária, sexo, período da graduação, ano de graduação e área de atuação. A segunda parte incluiu as evocações livres de palavras, que buscou apreender as representações dos sujeitos participantes do estudo frente ao termo indutor: pensar na profissão de terapia ocupacional. A terceira consistiu em solicitar aos participantes que apresentassem uma justificativa para a escolha da palavra mais importante. Para os graduandos, os questionários foram aplicados de forma coletiva em sala de aula. As instruções foram dadas ora em grupo, ora individualmente, obedecendo às circunstâncias. Já para os egressos, os questionários foram aplicados individualmente via redes sociais, em tempo real, por meio de chat, cujas instruções foram dadas obedecendo ao procedimento utilizado com os discentes.

2 O projeto foi avaliado pelo Comitê de Ética e Pesquisa da Universidade Estadual de Montes Claros conforme recomenda a Resolução n. 466/12 do Conselho Nacional de Saúde e aprovado sob o número 846.386. 
Os dados sobre o perfil dos participantes e os termos evocados foram transcritos para o programa Microsoft Office Excel 2007, o que permitiu a construção de uma planilha para a adequação do banco de dados, necessária para o processamento e análise pelo software Essemble de Programmes Permettant l'Analyse de Évocations (EVOC), versão 2005, composto por um conjunto de programas ordenados para o processamento e análise matemática das evocações (Vergés como citado em Sarubbi et al., 2013).

O tratamento dos dados permitiu a construção do quadro de quatro casas de Vérges, que descreve: o núcleo central (elementos mais frequentes e mais importantes situados no quadrante superior esquerdo); os elementos intermediários ou primeira periferia (elementos periféricos mais importantes situados no quadrante superior direito); os elementos de contraste (com baixa frequência, mas considerados importantes pelos sujeitos, situados no quadrante inferior esquerdo); e os elementos periféricos da representação ou segunda periferia (elementos menos frequentes e menos importantes, localizados no quadrante inferior direito), organizados de acordo com a frequência mínima e a Ordem Média de Evocações (OME).

Com o objetivo de trabalhar com os dados de diferentes arquivos, de forma a compará-los (dois arquivos por vez), utilizou-se o programa Complex (Sarubbi et al., 2013). Assim, o arquivo contendo todas as evocações foi comparado aos dos três subgrupos: discentes dos períodos iniciais, dos períodos finais e egressos.

Para ampliação e mapeamento das evocações encontradas no quadro de quatro casas de Vergès, utilizou-se a análise hierárquica por similaridade e a análise de implicação processadas pelo software Classification Hiérarchique Classificatoire et Cohésitive (CHIC@), versão 4.1, que possibilita a construção de um grafo que contém vetores indicadores da força da correlação entre as variáveis analisadas, cujo dados também foram transcritos para o programa Microsoft Office Excel 2007, o que permitiu a construção de uma planilha para a adequação do banco de dados necessária para o processamento e análise pelo software.

\section{Resultados}

A amostra foi composta predominantemente pelo sexo feminino $(91 \%)$, nos três subgrupos estudados. No grupo de egressos, houve predomínio das áreas de desenvolvimento infantil $(34,3 \%)$ e saúde mental $(31,2 \%)$, no que se refere a sua área de atuação profissional.

O quadro de quatro casas gerado pelo EVOC indica que as palavras "autonomia", "cuidado", "funcionalidade", "independência", "ocupação" e "reabilitação" formam o núcleo central da representação. As três casas seguintes representam a zona de periferia constituída pelas palavras "atividade", "atividade de vida diária" ou AVD, "contexto", "inclusão", "adaptação", "amor", "bem-estar", "cotidiano", "qualidade de vida" e "saúde". Contudo, cabe destacar que as palavras "contexto" e "inclusão", além de fazerem parte da periferia, se encontram em uma zona conhecida como zona de contraste. 


\section{Figura I. Quadro de quatro casas - distribuição pela frequência e ordem média de posição gerado pelo Rangfrq-EVOC.}

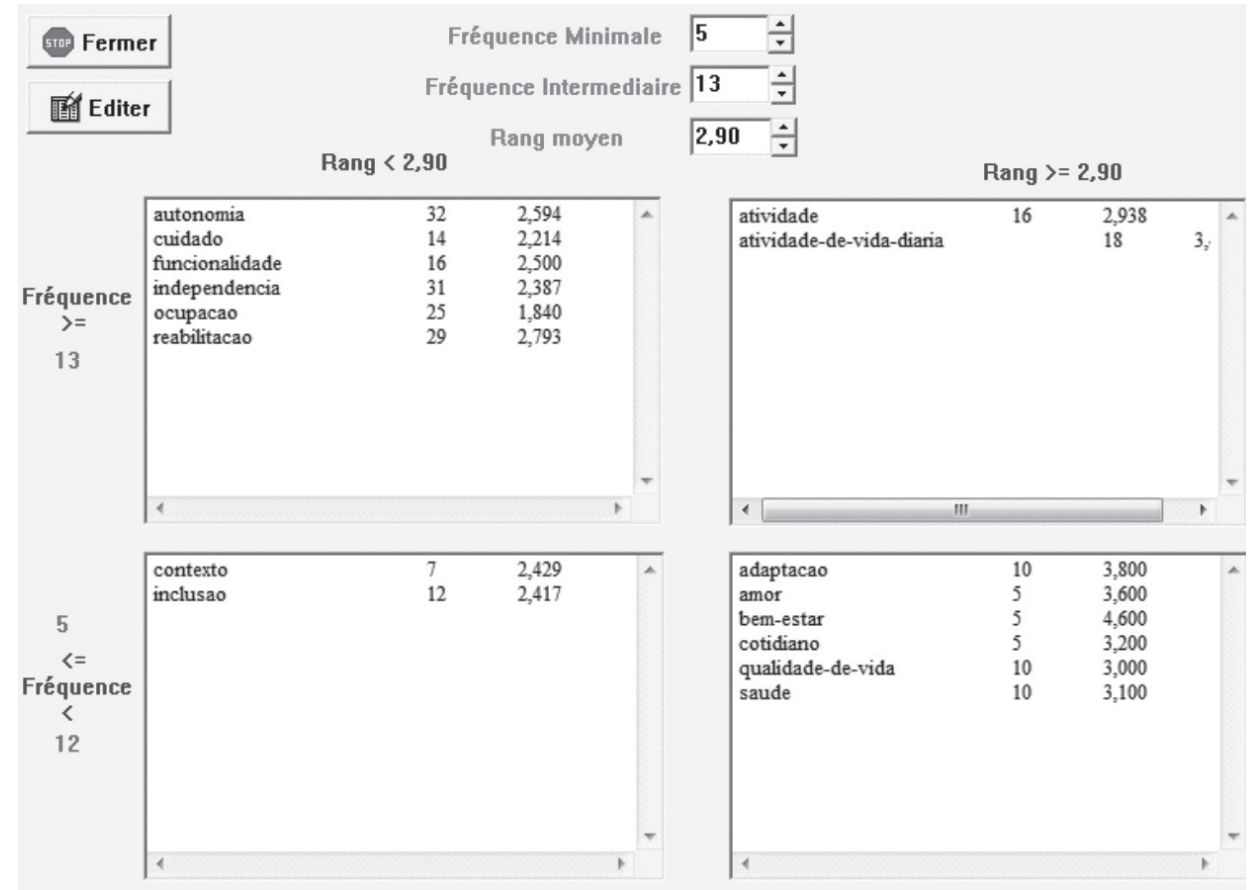

Fonte: Output Rangfrq-EVOC.

Na sequência, os dados foram submetidos ao programa Complex, por meio do qual o arquivo contendo todas as evocações $(n=213)$ foi comparado aos três subgrupos - discentes dos períodos iniciais, finais e os egressos. Os dados revelam que as evocações são distintas entre os subgrupos quando comparados. As palavras "reabilitação" e "ocupação" apresentam baixa frequência de evocação para os egressos, diferente da palavra "qualidade de vida", que apresenta alta ocorrência. Já a palavra "inclusão" apresenta alta frequência para o subgrupo dos iniciantes. Importante destacar que algumas evocações apresentam frequência 0 , como é o caso da AVD para o subgrupo dos iniciantes e "qualidade de vida" e "amor" para o subgrupo dos finais. Também para esse último grupo, diferente de zero, mas com baixa evocação (1) está a palavra "cuidado".

Das 16 evocações encontradas no quadro de quatro casas, apenas 12 foram submetidas ao software $\mathrm{CHIC} \circledast$, uma vez que optou-se por incluir as evocações que tivessem frequência superior a 10. Esse critério foi adotado porque a frequência menor 10 resultaria em dados inconsistentes e distorções da árvore hierárquica e do grafo. Os termos excluídos foram "contexto", "amor", "bem-estar", "cotidiano". 
Gráfico I. Árvore hierárquica de similaridade das categorias.

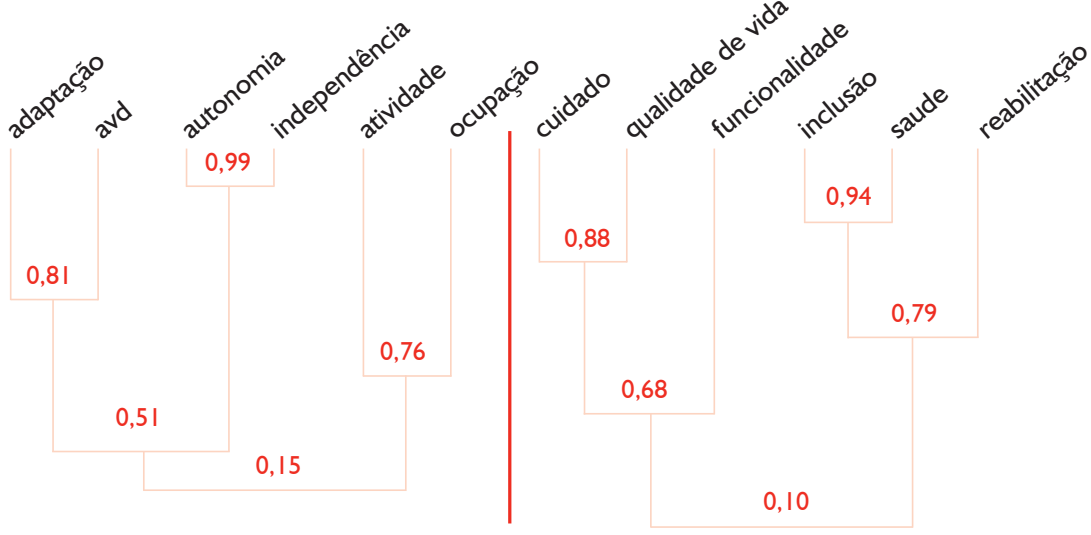

Fonte: Output CHIC®.

Observamos que, na árvore de similaridade, há dois grandes grupos que não apresentam ligação entre si, um composto pelos termos "adaptação", AVD, "autonomia", "independência", "atividade" e "ocupação", e outro composto por "cuidado", "qualidade de vida", "funcionalidade", "inclusão", "saúde" e "reabilitação".

O gráfico 2 mostra os vetores de implicação que correlacionam as evocações segundo o índice de confiança, em que três grupos (A, B e C) e dez caminhos (direção das setas) foram identificados pelo software. Além disso, utilizando o programa, foi possível identificar quantos e quais indivíduos, distribuídos entre iniciantes, finais e egressos, contribuíram para a formação de cada caminho, e, por consequência, de cada grupo ( $A, B$ e $C$ ).

Gráfico 2. Grafo de implicação das categorias gerada pelo CHIC ${ }$.

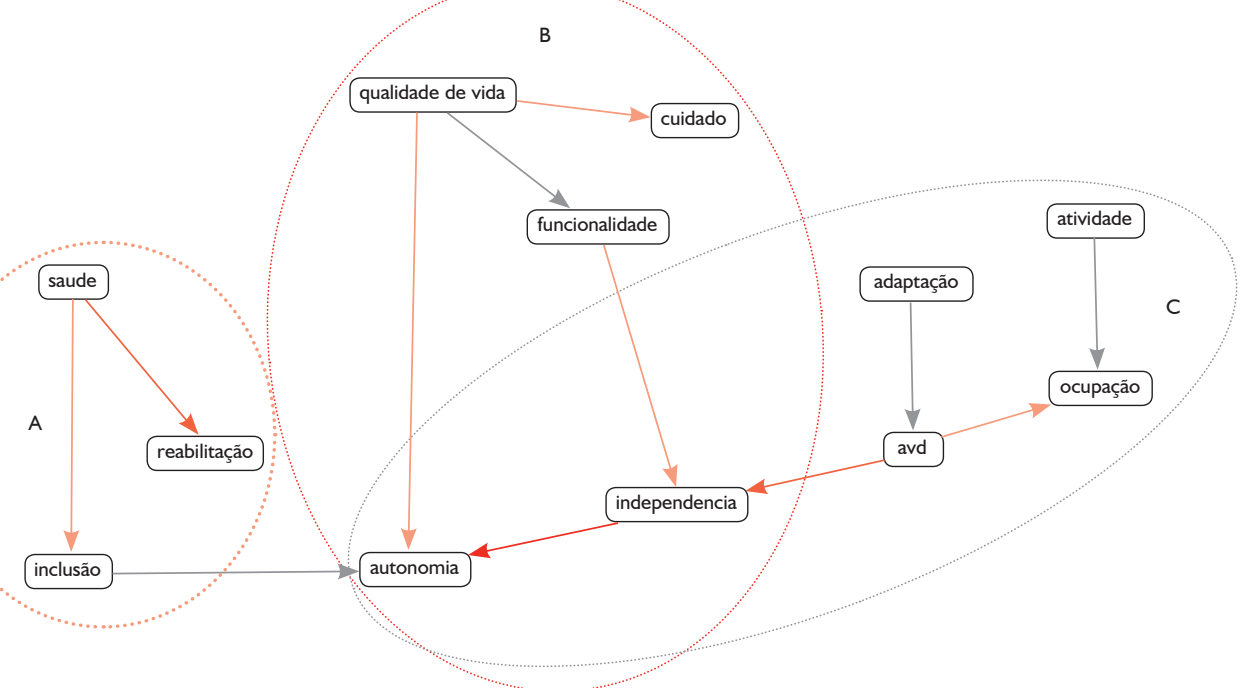

Fonte: Elaborado pelos autores. 
Observa-se que o caminho independência-autonomia $(0,98)$ é interface entre os grupos B e C, e que os três grupos possuem vetores que convergem para a palavra "autonomia". Outro ponto de destaque é que a associação entre autonomia e independência é a mais forte de todas $(0,98)$, demonstrado que quem fala em autonomia também fala em independência. Essas duas palavras aparecem associadas e ditas pelo grupo pesquisado como um todo, de forma bastante persistente.

\section{Discussão}

Para Abric (2003), uma representação social é um conjunto organizado e estruturado de informações, crenças, opiniões e atitudes, que constitui um sistema sociocognitivo particular, composto de dois subsistemas: um sistema central (ou núcleo central) e um sistema periférico. O sistema central é estável, coerente, consensual e historicamente determinado; e o sistema periférico é, por sua vez, flexível, adaptativo e relativamente heterogêneo quanto ao seu conteúdo. O sistema central é o que caracteriza uma representação em si e procurá-lo é, então, procurar a raiz, o fundamento social da representação, que, em seguida, se modulará, diferenciará e individualizará no sistema periférico.

O quadro de quatro casas indica que a representação sobre a profissão de terapia ocupacional é fortemente marcada por elementos voltados à atuação desses profissionais. Ao pensarem na profissão, os sujeitos priorizam os aspectos técnicos e práticos, em detrimento aos aspectos psicológicos e comportamentais que estariam relacionados ao "ser" profissional. Ao evocarem "autonomia", "cuidado", "funcionalidade", "independência", "ocupação", "reabilitação", "atividade", AVD, "contexto", "inclusão", "adaptação", "qualidade de vida" e "saúde", evidencia-se que o propósito é promover, possibilitar e facilitar tais elementos na vida de seus clientes, destacando aqui, a ideia do fazer profissional. A única exceção encontrada foi o termo "amor", que está relacionado com o ser profissional. Essa palavra é entendida como condição indispensável para a qualidade da execução do trabalho do terapeuta ocupacional, além de aparecer como fator motivacional para que o profissional continue a exercer seu trabalho.

De acordo com Lima (s.d., p. 7), "o amor e o prazer no trabalho são identificados como a principal e indispensável motivação para a busca de aprimoramento profissional, subordinando até mesmo a busca de formação e profissionalização". Contudo, no que tange à qualidade da execução do trabalho, é necessário também o aparato teórico e técnico oferecido pelos fundamentos científicos da profissão (Aota, 2015).

O núcleo central está composto pelos termos "autonomia", "cuidado", "funcionalidade", "independência", "ocupação" e "reabilitação". Agruparam-se assim, os elementos mais frequentes e os mais importantes. No entanto, esses elementos não são equivalentes entre si, sendo alguns mais importantes que outros. Os resultados do Complex-EVOC nos permitem compreender melhor essas relações.

Entre as palavras que compõem o núcleo central, somente os termos "autonomia" e "independência" apresentaram alta representatividade nos três subgrupos que as 
evocaram mais vezes e nas primeiras posições. Durante toda a sequência da análise dos dados, esse binômio se destaca, como observado também na árvore hierárquica. O par representou a maior similaridade $(0,98)$, indicando que os sujeitos, ao evocarem as palavras "autonomia" e "independência", as evocaram juntas. O extremo dessa associação evidencia-se nas evocações de um dos participantes que tratou "autonomia" e "independência" como um único termo. Essa associação contribui também para a formação do vetor mais forte do grafo de implicação $(0,98)$, principalmente entre dois grupos (B e C), e que todos os vetores constituem caminhos que convergem para a palavra "autonomia".

Ao justificar a importância das palavras "autonomia" e "independência", 48\% dos sujeitos fazem referência uma a outra. A título de exemplo, citamos um participante que, ao definir "independência", apresentou o conceito de "autonomia": "escolher fazer uma atividade por vontade ou necessidade é um passo muito importante".

O que pode explicar a associação entre essas duas palavras é o fato de as DNC para o curso de Terapia Ocupacional apresentarem no artigo quinto, parágrafo I, a autonomia como um dos principais objetivos a serem atingidos pelos planos de ação e tratamento para a população com a qual o terapeuta ocupacional trabalha. Já o parágrafo XXIV traz um conceito de autonomia que não apareceu na perspectiva dos sujeitos entrevistados. Esse parágrafo trata da necessidade do profissional desenvolver habilidades pessoais e atitudes necessárias para a prática profissional, entre elas, a autonomia intelectual (Conselho Nacional de Educação, 2002).

No PPP do curso de graduação em terapia ocupacional da UFMG, as palavras autonomia e independência aparecem relacionadas ao objetivo do profissional para com a sua clientela e em seu cotidiano, na execução de suas ocupações. Nesse documento, na parte relacionada ao perfil profissional, encontra-se entre as aptidões do terapeuta ocupacional a capacidade de atuar "priorizando ações que promovam a autonomia/ independência dos clientes, a fim de que alcancem uma melhor qualidade de vida e participação social" (Universidade Federal de Minas Gerais, 2008. p. 15). Na descrição das competências e das habilidades específicas dos terapeutas ocupacionais, esses dois termos mantêm o significado, porém com o foco na orientação da família/cuidador para mais independência e autonomia do cliente.

A título de complementação, nos referimos também ao documento Estrutura da Prática da Terapia Ocupacional: Domínio e Processo (2015) da Associação Norte-Americana de Terapia Ocupacional (em inglês American Occupational Therapy Association - Aota). Nesse documento, a palavra autonomia aparece apenas uma vez inserida no conceito de Prática Centrada no Cliente, que, apesar de ser abordada em sua amplitude, permanece como um conceito voltado para o cliente.

Nesse mesmo documento, os profissionais de terapia ocupacional consideram os clientes independentes, seja por desempenharem os componentes das atividades por si só, seja por desempenharem a ocupação em um ambiente adaptado ou modificado, usando vários dispositivos ou estratégias alternativas, ou ainda, quando supervisionarem a conclusão da atividade por outros (Aota, 2015). 
Por fim, os estudos de Lycett (1990) e Farinha e Silva (2005), citados por Carvalho (2010), indicam que os termos autonomia e independência são as palavras mais frequentes usadas pelos profissionais para definirem a terapia ocupacional, o que corrobora os resultados obtidos no grupo estudado.

Outra palavra que se destaca no núcleo central é "ocupação". Os resultados do Complex-EVOC mostraram que os egressos não consideram esse termo tão importante quando comparado aos iniciantes e finais. Esse dado merece aprofundamento, uma vez que a terapia ocupacional, é definida pelo uso terapêutico da ocupação. No PPP, é apresentado o eixo conceitual da profissão adotado no curso, que cita o perfil do terapeuta ocupacional como aquele que incorpora os construtos teóricos e práticos que guiam a terapia ocupacional, focando na relação entre o indivíduo e a ocupação em diferentes contextos. Esse dado sugere que a representatividade do termo "ocupação" está presente no decorrer da formação profissional, mas diminui ao longo da atuação dos terapeutas ocupacionais (Universidade Federal de Minas Gerais, 2008).

$\mathrm{Na}$ árvore hierárquica (Gráfico 1), os termos "ocupação" e "atividade" vêm associados $(0,60)$, indo ao encontro da literatura, uma vez que "o termo ocupação denota envolvimento na vida construído por múltiplas atividades" (Aota, 2015, p. 6). No grafo de implicação (Gráfico 2), observamos um resultado diferente ao do Complex-EVOC, pois as contribuições para a força da ligação ocupação-atividade $(0,57)$ são feitas pelo subgrupo dos anos finais e egressos, sendo a força da ligação fraca e demostrando pouca representatividade no grupo como um todo.

$\mathrm{Na}$ literatura, encontramos estudos com resultados semelhantes. Lycett (1990), citado por Carvalho (2010), concluiu que não existe uma abordagem comum na explicação de terapia ocupacional, e mais da metade dos participantes de seu estudo referiram ter dificuldades em explicar o seu trabalho. Caniglia (2005) demonstrou que a terapia ocupacional se perde em longas definições, muitas vezes incompreensíveis, e que a forma como alguns profissionais e algumas associações de classe definem a terapia ocupacional chega a ser um problema para a formação da identidade profissional.

Diante desse contexto visando definições mais precisas da terapia ocupacional, seja pela estruturação curricular das disciplinas ofertadas, seja pela maior aproximação de discentes e egressos, é necessário que os cursos incentivem debates entre serviços, os demais profissionais de saúde e os atores diretamente envolvidos no processo formativo, de maneira a refletir os vários aspectos que orientam a profissão.

Na primeira periferia, estão "atividade" e AVD, que são considerados os elementos periféricos mais importantes. Os resultados do Complex-EVOC mostram que o termo AVD apresentou frequência zero entre os iniciantes. Entretanto, destaca-se que para a terapia ocupacional, AVD são "atividades [...] que as pessoas executam enquanto indivíduos, nas famílias e em comunidades para ocupar o tempo e trazer significado e propósito à vida" (Aota, 2005, p. 5). Elas também são "[...] fundamentais para viver no mundo social; e permitem a sobrevivência básica e o bem-estar" (Aota, 2015, p. 19). Considerando a importância desse conceito para terapia ocupacional, vale questionar 
o porquê desse resultado. Nesse sentido, foi necessário recorrer à grade de disciplinas do curso de terapia ocupacional da UFMG para identificar variáveis presentes no currículo que pudessem justificar esse resultado.

A análise do currículo sugere que esses sujeitos não evocam o termo AVD porque ainda não tiveram nenhuma disciplina cujo conceito tivesse sido trabalhado. Levando em consideração que esse conceito permeia várias outras disciplinas, é provável que esse subgrupo (iniciantes) tenha conhecimento da terminologia, mas que ela não está inserida em suas representações da profissão, pois será contemplada somente no terceiro período, especificamente, na disciplina "Estudos das atividades de vida diária".

Na árvore hierárquica (Gráfico 1), AVD e "atividade" fazem parte do mesmo grupo, mas formam pares com outros termos. AVD, por exemplo, forma par com "adaptação". A similaridade entre essas palavras pode estar relacionada à necessidade de se fazer alguma adaptação (seja na tarefa, seja no ambiente, seja no sujeito) que permita aos indivíduos executarem as AVD de maneira autônoma e, assim, alcançar qualidade de vida.

A associação da "atividade" com "ocupação" na árvore hierárquica (Gráfico 1) aparece quando entende-se atividade como um recurso para modificar e/ou melhorar o ser humano, e ocupação como toda atividade executada pelos seres humanos com a função de preencher o tempo ocioso e dar sentido à vida, tornando-o um indivíduo ativo. Na literatura, a associação desses termos é clara, pois os "profissionais de terapia ocupacional possibilitam a participação do cliente pela modificação de uma tarefa, de um método de realização da tarefa e do ambiente para promover o envolvimento na ocupação" (Aota, 2015, p. 41).

Tomando a estrutura curricular como possível fator de influência na representação dos discentes, o termo "inclusão", presente na zona de contraste, também merece destaque. Embora essa palavra tenha sido evocada por um número menor de sujeitos, quando ocorre, aparece nas primeiras posições. Tal dado pode sugerir que uma ou mais parcelas da amostra, ou seja, uma minoria, evocam termos que têm uma posição importante, mas que não são citados pela maioria, exprimindo o contraste de ideias de uma parte do grupo em relação ao grupo como um todo (Sarubbi et al., 2013).

O subgrupo identificado como portador dessa representação foi o dos iniciantes, mais precisamente, os discentes do segundo período. Ao analisarmos o que esses indivíduos entendem por inclusão, observa-se que o significado corresponde ao de inclusão social: a inclusão dos indivíduos nas escolas, nas empresas, em suas casas, na sua vizinhança etc. Visando identificar possíveis justificativas para essa evocação, recorremos à estrutura curricular, na qual verificamos que esses sujeitos estavam cursando uma disciplina denominada Processo de inclusão social, a qual aborda o conceito evocado.

Apesar de a segunda periferia ser constituída pelos elementos menos frequentes e menos importantes, o termo "qualidade de vida" chama a atenção por ter baixa representatividade entre os discentes (iniciantes $=2$ evocações, finais $=0$ evoca- 
ções) e alta representatividade entre os egressos, quando comparado à frequência total. Esse resultado sugere que pensar em qualidade de vida, aqui entendida como qualidade de vida do cliente, estado de bem-estar e saúde, é algo que sofre influência da prática algo considerado importante por aqueles que se encontram em exercício profissional.

$\mathrm{Na}$ árvore hierárquica (Gráfico 1), "qualidade de vida" aparece associada a "cuidado" $(0,68)$ e esse par à "funcionalidade" $(0,58)$. Sugere-se que a similaridade entre os termos "cuidado", "qualidade de vida" e "funcionalidade" está presente na subjetividade do ser humano, que é considerada no processo do tratamento, bem como ser foco do terapeuta ocupacional durante sua atuação profissional. Atribui-se à funcionalidade, o meio para alcançar a qualidade de vida. Essas associações no grafo de implicação aparecem com o termo "qualidade de vida" dando origem a três caminhos distintos, com fracas ligações $(0,61 ; 0,61$ e 0,57$)$, que são formadas, em sua maioria, pelo subgrupo dos egressos como mostrado nos resultados do Complex-EVOC.

O curioso é que tanto o PPP quanto a Estrutura da Prática da Terapia Ocupacional: Domínio e Processo (Aota, 2015) apresentam a qualidade de vida como algo essencial a ser promovida e/ou melhorada. Isso sugere que é na prática que essa representação é construída ou, ainda, que, apesar de preconizado nos documentos, essa temática não está contemplada de maneira satisfatória nas disciplinas do curso estudado.

Esse resultado chama atenção para o fator da formação profissional. Isso porque está preconizado nas DCN para os cursos de saúde, que os discentes e profissionais devem desenvolver competências e habilidades para atuar na resolução dos problemas de saúde dos indivíduos e da coletividade (Conselho Nacional de Educação, 2002), portanto, devem estar aptos a atuarem com qualidade e resolubilidade no SUS. Para tal, iniciativas voltadas para as mudanças na graduação, por meio da construção de projetos pedagógicos e currículos mais flexíveis e inovadores, com potencial para reorientar a formação, entraram em vigor a partir desse documento. Nesse sentido, ao observarmos o quadro de quatro casas, vemos que os termos relacionados à promoção e à saúde são "qualidade de vida", "bem-estar" e "saúde", localizados na segunda periferia. Esse resultado está coerente, uma vez que o sistema periférico é funcional, e, graças a ele, a representação pode ancorar na realidade do momento (Sá, 2002).

Portanto, como as DCN e o PPP são instrumentos que materializam as políticas de saúde recentes, é esperado que os termos que fazem menção à atenção básica estivessem nas periferias. A análise revelou elementos que, mesmo com frequências reduzidas, indicam conteúdos importantes.

\section{Conclusão}

Conforme exposto anteriormente, dos termos evocados que compõem o núcleo central, somente "autonomia" e "independência" apresentam grandes possibilidades de fazerem parte da representação social do grupo estudado. O termo "inclusão" parece fazer parte da representação do subgrupo dos iniciantes e "qualidade de vi- 
da", para o subgrupo dos egressos, possivelmente, é uma representação construída no campo do trabalho.

Os resultados obtidos indicam que o presente estudo atingiu seus objetivos ao evidenciar a possível representação social sobre a profissão de terapia ocupacional dos discentes e egressos do curso de terapia ocupacional da UFMG. Entretanto, um estudo comparativo que envolvesse outras instituições de ensino superior (IES) que ministram o curso de terapia ocupacional poderia oferecer uma visão mais aprofundada das representações sociais da profissão e os mecanismos envolvidos em sua construção. Outro fator que poderia contribuir para uma melhor compreensão dessa questão seria a inclusão na análise documental de outras fontes como os documentos do Pró-Saúde e Pet-Saúde, que contribuem para a implantação das DCN nas Instituições de Ensino Superior (IES).

Observou-se também que os discentes e egressos, ao representarem a profissão, priorizam o "fazer" profissional em detrimento do "ser" profissional, o que pode estar relacionado à dificuldade em definir e criar uma identidade profissional. A ênfase no fazer pode ser decorrente de uma visão tecnicista da profissão, na qual a cisão profissional/paciente, a normatização e a despersonalização das práticas se fazem mais intensas. Nesse contexto, o fazer se dissocia do ser, e o exercício da profissão não favorece a constituição do profissional/sujeito.

Os terapeutas ocupacionais em exercício, por meio de suas evocações, mostraram que a prática também influencia a forma como a profissão é representada. Esse resultado indica que o processo formativo se estende para além da universidade, em que novas representações da profissão podem ser construídas nos contextos da prática.

Entendendo que as representações sociais da profissão estão na base da formação da identidade profissional e que essa, além de garantir a especificidade da profissão, orienta comportamentos e práticas profissionais (Sá, 2002), conclui-se que as representações focadas no fazer não permitem que os terapeutas ocupacionais encontrem no exercício da profissão possibilidades de se colocarem como sujeitos, o que pode resultar em práticas despersonalizadas, mecânicas e pouco humanizadas.

\section{Referências}

Abric, J. C. (2003). Abordagem estrutural das representações sociais: desenvolvimentos recentes. In P. H. F. Campos, \& M. C. S. Loureiro (Org.). Representações sociais e práticas educativas. Goiânia: Editora da UCG, p. 37-57.

Aota. American Occupational Therapy Association. (2015). Estrutura da prática da terapia ocupacional: domínio e processo. $3^{a}$ ed. Revista de Terapia Ocupacional da Universidade de São Paulo, 26(Ed. especial), pp. 1-49. doi: http://dx.doi. org/10.11606/issn.2238-6149.v26iespp1-49.

Bardin, L. (2011). Análise de conteúdo. (Ed. rev. e ampl.). São Paulo: Edições 70. 
Branco, M. F. F. C. (2003). Terapeuta ocupacional: construção de uma identidade profissional. Dissertação de Mestrado, Centro de Filosofia e Ciências Humanas, Universidade Federal de Pernambuco, Recife, Pernambuco, Brasil.

Caniglia, M. (2005). Terapia ocupacional - um enfoque disciplinar. Belo Horizonte: Ophicina de Arte e Prosa.

Carvalho, C. R. A. (2012, abr.-jun.). A identidade profissional dos terapeutas ocupacionais: considerações a partir do conceito de estigma de ErvingGoffman. Revista Saúde eSociedade, 21(2), 364-371. doi: http://dx.doi.org/10.1590/\$0104-12902012000200010.

Carvalho, C. R. A. (2010). A atuação dos terapeutas ocupacionais em unidades públicas de saúde da cidade do Rio de Janeiro. Dissertação de Mestrado, Escola Nacional de Saúde Pública Sergio Arouca, Fundação Oswaldo Cruz, Rio de Janeiro, Brasil.

CHIC, Classification Hiérarchique Classificatoire et Cohésitive, Versão 4.1.Software.

Conselho Nacional de Educação, Pub. L. No. 1.133, § 1E, Diário Oficial da União (2001).

Conselho Nacional de Educação, Pub. L. No. 6, § 1, Diário Oficial da União (2002).

Nikel, R. (2007). Terapia ocupacional em Curitiba e região metropolitana: trajetória e processo de formação. Tese de Doutorado, Setor de Educação, Universidade Federal do Paraná, Curitiba, Brasil.

Novaes, A. O., \& Sousa, C. P. (2013). Protagonismo? - identidade e representações sociais de estudantes de pedagogia sobre o Brasil. In A. Arruda, \& C. P. Sousa (Org.). Imaginário e representação social de universitários sobre o Brasil e a escola Brasileira: um estudo construído com múltiplas possibilidades. São Paulo: Annablume; Fundação Carlos Chagas.

Lima, N. N. (s.d.). Amor à profissão, dedicação e o resto se aprende: significados da docência em educação infantil na ambiguidade entre a vocação e a profissionalização. p.1-17. Recuperado em 15 setembro, 2015 de http://29reuniao.anped. org.br/trabalhos/trabalho/GT07-2570--Int.pdf.

Oliveira, D. C., Marques, S. C., Gomes, M. T., \& Teixeira, M. C. T. V. (2005). Análise de evocações livres: uma técnica de análise estrutural das representações sociais. In A. S. P. Moreira, B. V. Camargo, J. C. Jesuíno, \& S. M. Nobrega. Perspectivas teórico-metodológicas em representações sociais. João Pessoa: UFPB, p. 573-603.

Sá, C. P. (2002). Núcleo das representações sociais. (2ª ed.) Petrópolis: Vozes.

Sarubbi Jr. V. S. et al. Desvelando o Programa EVOC 2000. In: Reis, A. O. A.; Junior, V. S.; Figueiredo Neto, M. M. B.; Figueiredo Neto, M. L. R. Tecnologias computacionais para o auxílio em pesquisas qualitativas. São Paulo: Schoba, 2013, p. 41-96.

Sarubbi, Jr. V. S. (2012). Representações sociais das equipes técnicas acerca do cuidado à criança nas creches da Universidade de São Paulo. Dissertação de Mestrado, Faculdade de Saúde Pública, Universidade de São Paulo, São Paulo, Brasil. 
Sarubbi, Jr. V. S. et al. Desvelando o Programa EVOC 2000. In: Reis, A.O.A.; Junior, V.S.; Figueiredo Neto, M.M.B.; Figueiredo Neto, M.L.R. Tecnologias computacionais para o auxílio em pesquisas qualitativas. São Paula: Editora Schoba, 2013, p.41-96.

Universidade Federal de Minas Gerais. Colegiado do curso de graduação em terapia ocupacional. (2008). Projeto pedagógico do curso de graduação em terapia ocupacional da Universidade Federal de Minas Gerais. Belo Horizonte, Minas Gerais, Brasil.

Submissão: 5.8 .2016

Aceitação: 11.4.2017 